\title{
A carreira moral da vergonha na visão de homens e mulheres "alcoólatras"
}

| ${ }^{1}$ Fernanda Vecchi Alzuguir |

Resumo: Neste artigo, analisamos a carreira moral de tratamento do alcoolismo em um serviço público de saúde a partir de depoimentos de homens e mulheres "alcoólatras" sobre a moral da vergonha. A carreira moral é a sequência de mudanças que produzem efeitos na identidade e no esquema de imagens da pessoa para julgar os outros e a si própria. Foram entrevistados 20 pacientes do serviço, sendo dez homens e dez mulheres em acompanhamento ambulatorial e/ou internados. Além disso, observações de campo das relações entre pacientes e destes com os profissionais de saúde foram conduzidas. Aspectos da carreira moral foram analisados, entre eles, a "conscientização" do alcoolismo como doença e da condição alcoólatra e a construção da vergonha e da responsabilidade no contexto de tratamento. A vergonha expressa o reconhecimento dos entrevistados da inobservância de normas sociais, entre as quais, a repercussão do gênero na definição da ética do homem provedor e da boa mãe. Comprovando a dimensão médico-moral do dispositivo terapêutico, a vergonha é reconfigurada nos momentos de (re) internação como expressão da desaprovação de um estilo de vida com a bebida, e se alia ao projeto terapêutico no sentido de dificultar a "recaída" e impedir a desmoralização alcoólatra. Concluímos que a medicalização do alcoolismo se inscreve num campo moral englobante, produtor de moralidades e formas particulares de perceber e agenciar o alcoolismo.

> Palavras chave: carreira moral; vergonha; alccolismo; tratamento.
1 Psicóloga, mestre e doutora em Saúde Coletiva pelo IMSUERJ. Rio de Janeiro. Brasil. Endereço eletrônico. fevecchi@ gmail.com 
Eu não faço muita questão de esconder também. Eu, na época, eu já senti muita vergonha. Mas depois que eu conheci o hospital, essa vergonha, as minhas psicólogas, psiquiatras, elas conseguiram tirar da minha mente a vergonha que eu sentia. Ela disse: "Não sinta vergonha, não se sinta a pior, a pior, o pior dos piores, você apenas tem uma doença, é como se fosse um diabetes, como se fosse uma pressão alta, como se fosse um câncer. É uma doença, você não tem culpa, você não tem culpa de ser alcoólatra, não tenha vergonha." Isso, elas falam diariamente.

Carmem, 42 anos, várias internações, internada no momento da entrevista, tratamento de longa data.

Neste artigo ${ }^{1}$, apresentamos algumas reflexões sobre uma forma de moralidade particular que permeia o universo cultural de homens e mulheres "alcoólatras" em contexto hospitalar de tratamento para o alcoolismo e que têm, na moral da vergonha, sua expressão privilegiada. Esse sistema moral que se desenha em torno do alcoólatra e do alcoolismo, entendidos como categorias médicas em construção, será analisado em sua relação com a carreira moral de tratamento no âmbito do serviço de um hospital da rede pública de saúde mental do Rio de Janeiro, o qual denominamos Serviço de Alcoolismo.

A carreira moral é definida por Goffman (1996) como a sequência de mudanças que produzem efeitos na identidade e no esquema de imagens da pessoa para julgar os outros e a si própria. Trata-se de um conceito especialmente útil para a compreensão de como a trajetória dos alcoólatras pelas instituições de enfrentamento do alcoolismo realiza uma espécie de reordenação moral. ${ }^{2}$ Assim, o conceito de carreira moral reflete a observação de que o percurso de homens e mulheres por instituições, tais como o conhecido grupo de ajuda mútua Alcoólicos Anônimos (AA) e o Serviço de Alcoolismo, exerce impacto significativo sobre a reconstrução da pessoa - através da construção gradual de sua identificação como indivíduo-doente - e do alcoolismo como doença.

O material analisado neste artigo é fruto de uma pesquisa de doutorado, para a qual foram realizadas entrevistas semiestruturadas com 20 pacientes do Serviço de Alcoolismo, no período de agosto de 2007 a abril de 2008, dos quais dez homens e dez mulheres em tratamento ambulatorial e/ou internados. E, também, de observações das relações cotidianas entre profissionais e pacientes e destes entre si, nos espaços oficiais de tratamento (grupos terapêuticos) e de conversas informais no âmbito hospitalar. Um Termo de Consentimento Livre 
e Esclarecido foi apresentado e assinado pelos entrevistados antes do início

das entrevistas e das observações dos grupos terapêuticos, explicitando-lhes a confidencialidade dos dados colhidos e o direito a eles assegurado de entrar e sair da pesquisa em qualquer momento que desejassem.

A fim de preservar o anonimato, todos os nomes citados são fictícios. Os informantes da pesquisa são provenientes de camadas populares e médias urbanas. Determinados aspectos da trajetória deles acentuam a interpenetração de valores e crenças distintas do grupo social de origem, como é o caso das mudanças socioeconômicas e migratórias, e o encontro com os serviços médicos de saúde, que favorecem a assimilação do discurso médico-psicológico.

A faixa etária dos informantes variou entre 42 a 71 anos, com grande concentração na faixa dos 50 a 55 anos. Em relação à inserção institucional, sete homens e seis mulheres realizavam apenas acompanhamento ambulatorial no momento da entrevista, enquanto três homens e quatro mulheres estavam internados nas enfermarias do Serviço de Alcoolismo.

A maioria dos entrevistados já participou de algum grupo AA. Há também aqueles que frequentavam o AA simultaneamente ao Serviço de Alcoolismo. Para aqueles com um engajamento de longa data no AA, era muito forte a penetração da sua doutrina na maneira como construíam suas narrativas sobre o álcool e o alcoolismo. Eles distinguiam claramente os modelos de funcionamento e objetivos de ambas as instituições. Para Ricardo, ${ }^{3}$ por exemplo, enquanto o AA trabalha em um "nível empírico" ou de "observação", o Serviço de Alcoolismo é formado por profissionais de saúde, que trabalham no campo "científico", "psicanalítico" ou "terapêutico". ${ }^{4} \mathrm{~A}$ inserção de homens e mulheres no contexto de um serviço público de saúde é um grande marcador que os diferencia de outros indivíduos que bebem cotidianamente, sem, contudo, realizarem tratamento.

Da literatura na área das ciências sociais sobre o sistema de representações e práticas das instituições de combate ao alcoolismo e de seus participantes, autores como Antze (1987), Campos (2004), Drulhe (1988), Fainzang (1998, 2003, 2007), Garcia (2003a, 2003b, 2004), Mariz (1994a, 1994b, 2003) e Soares (1999) observam o papel das associações de ex-bebedores na reconstrução do passado alcoólico e na consequente produção de uma identidade alcoólica, cujos significados variam conforme o sistema de crenças de cada associação. 
Por exemplo, a partir da análise de um grupo AA, Garcia (2003a, 2003b, 2004) verifica que a participação no grupo promove a ressignificação do passado de bebida, no sentido de sua desclassificação ou acusação mediante a constituição de uma identidade oposta, que é a do "alcoólico passivo" (aquele que não bebe mais e adquiriu uma consciência sobre a "doença”). Tais sentidos são tecidos em uma trajetória linear de descenso, ruptura e ascensão. Em relação a um passado desregrado de bebida, o alcoólico passivo se situa como um novo ser ou convertido.

De acordo com Soares (1999) e Garcia (2004), a ideia de alcoolismo como uma doença crônica e incurável presente nos grupos AA facilita o ingresso nesses grupos. Para Soares (1999), os grupos AA contribuem para a produção de uma "vitimização afirmativa", condição esta que "desculpabilizaria" o beber. Mariz (2003) elucida que também no discurso dos membros das igrejas pentecostais, que associam o álcool/alcoolismo a um mal demoníaco, sua localização como uma instância aquém da vontade do sujeito propicia um alívio da culpa e favorece a autoestima dos seus membros.

Fainzang $(1998,2003$, 2007) verifica a especificidade das representações e formas de agenciamento do alcoolismo por parte de membros de uma associação francesa de ex-bebedores denominada Vie Libre, o que lhe permite falar de uma verdadeira cultura da abstinência. Nessa perspectiva, a autora diferencia seu estudo das análises sobre as maneiras de beber, delineando, assim, a especificidade de um sistema cultural que se constrói em torno da abstinência como um valor.

Tais estudos ilustram que a passagem pelas instituiçôes de combate ao alcoolismo transformam de maneira importante concepçôes de si e do mundo, permitindo, assim, a ressignificação da trajetória alcoólica simultaneamente à construção da identidade alcoólatra. Através da descrição de aspectos da carreira moral, mostraremos que a medicalização do alcoolismo no âmbito de um serviço público de saúde se inscreve em um campo moral englobante, produtor de moralidades e formas particulares de perceber e lidar com o alcoolismo.

\section{A construção do alcoolismo: entre o físico e o moral}

O depoimento de Carmem, na introdução deste artigo, expressa de maneira exemplar a repercussão do tratamento no sentido da organização moral em torno 
da identidade alcoólatra. Em seu depoimento, a neutralização do aspecto moral do alcoolismo ganha destaque, através das intervenções dos profissionais de saúde que retraduzem a dimensão moral da vergonha e da culpa para a dimensão médica e, desse modo, "desculpabilizam" o/a alcoólatra em razão de sua condição doente. Esta retradução favorece o ingresso e a permanência no tratamento, além de contribuir para sua eficácia devido ao seu efeito de desestigmatização.

No entanto, uma análise isolada do relato de Carmem poderia sugerir uma relação de oposição entre a compreensão do alcoolismo como doença e sua construção moral. Diferentemente, uma análise global e aprofundada dos depoimentos indica uma relação mais complexa e intrincada que contraria aquela oposição, motivo pelo qual destacamos a ideia de retradução moral sob a linguagem da doença, ao invés do descarte do domínio moral. Contrariando, portanto, visões correntes na literatura biomédica, a análise demonstra como as dimensões médica e moral estão de fato interligadas na construção do alcoolismo, de forma que é pertinente considerá-lo como uma perturbação físico-moral.

Segundo Duarte (1988), a noção de perturbação traduz o esforço de relativização antropológica do fenômeno da doença tal qual definido pela cultura ocidental moderna, ampliando o campo de análise para outras formas de experiência do sofrimento, marcadas por um modo relacional de determinação das identidades (ao invés do modo individualista a partir do qual a biomedicina se constituiu).

Por plano físico, designamos as representações biomédicas do alcoolismo como doença. Já o plano moral compreende as reciprocidades sociais que configuram o sistema de valores do/a bebedor/a e o modo como ele/a é percebido/a socialmente. A moral da vergonha se destaca como via de compreensão deste eixo discursivo, e por isso sua análise será privilegiada neste artigo. A despeito da aparente supremacia da concepção biomédica do alcoolismo, argumentamos que o dispositivo terapêutico se inscreve num campo moral, donde concluímos que tal dispositivo é, ele próprio, um sistema físico-moral de construção do alcoolismo e da pessoa alcoólatra.

A "conscientização" de que o alcoolismo é uma doença, a construção da vergonha em relação ao passado alcoólico, da responsabilidade em relação ao tratamento e a "desculpabilização" pela doença são repercussões da carreira moral alcoólatra, as quais serão apresentadas a seguir. 


\section{A conscientização da doença e da condição doente}

Eu sei que eu sou uma pessoa doente e que eu preciso de tratamento. (Francisco, 52 anos, tratamento ambulatorial no momento da entrevista, inserção de longa data no Serviço de Alcoolismo. $)^{5}$

A internação em uma instituição total ${ }^{6}$ é um acontecimento significativo na redefinição das concepções do eu da pessoa. Para Goffman (1996), é nesse momento que se opera a passagem para a condição de paciente, tornando a posse de um estigma em particular um fato incontestável não só para os outros como para a própria pessoa em questão, tendo em vista o caráter público de que a internação se reveste. Indivíduos com um estigma particular tendem a passar por experiências semelhantes de aprendizagem e mudanças relativas à concepção do eu. $\mathrm{O}$ autor ilustra a noção de carreira moral a partir de seu estudo em hospitais psiquiátricos, nos quais observou a construção do status de doente/doença mental pela operação de forças sociais como, por exemplo, as circunstâncias similares a que os internos são submetidos de modo a responderem da mesma forma que os demais, a despeito de suas diferenças.

Comprovando a relevância da inserção no Serviço de Alcoolismo como evento marcante no processo de construção da identidade alcoólatra, informantes como Pedro e Francisco passaram "a saber" que eram alcoólatras nas consultas psiquiátricas. Pedro, por exemplo, "descobriu” que era alcoólatra no terceiro dia de sua primeira internação, após a psiquiatra dizer que ele sofria de um problema de alcoolismo grave. Sobre isso, Pedro relata: "Na época em que eu conheci o hospital, eu já tinha tido uma crise de alcoolismo, mas eu não sabia que eu era alcoólatra, que eu tinha problema de álcool. Bebia muito, mas eu não sabia que era um problema. Eu achava que eu não tinha problema."

Carmem comenta sobre um momento anterior à consolidação da consciência de ter uma doença e o impacto da intervenção médica em direção àquela consolidação. Ela relata: "Aí foi depois que eu saí da umbanda que eu comecei realmente a cair feio no álcool, e aí eu comecei a beber muito [...] eu não me julgava uma alcoólatra." Mais adiante, ela retoma: "Porque a bebida me aliviava. Então, ao invés de eu ir no médico pra pegar remédio, ou uma coisa assim, que eu não sabia que era uma doença, eu tomava a bebida..."

Para aqueles com longo tempo de inserção institucional, a forte penetração da identidade alcoólatra pode ser verificada a partir da estranheza em relação 
à pergunta: "Você se considera alcoólatra?" A naturalização dessa identidade é comprovada pela resposta de Pedro: "Se eu me considero, não, eu sou alcoólatra". Ou pela resposta de Ana: "É uma doença que não sou eu que digo", referindo-se à catalogação do alcoolismo como doença por parte da Organização Mundial da Saúde. Ana, portanto, destaca que a identificação do alcoolismo como doença ultrapassa um nível pessoal e empírico, sendo um fato cientificamente comprovado.

O emprego do verbo "considerar" não parece tão adequado, já que dá margem a uma opinião pessoal, como se ser ou não alcoólatra fosse uma questão de escolha. Diferentemente, a resposta de Pedro mostra que ser alcoólatra é visto como uma condição previamente estabelecida. A fixação da identidade alcoólatra condiz com a teoria da doença do AA, segundo a qual o alcoolismo é uma doença genética, progressiva e incurável; portanto, uma condição cuja etiologia independe da vontade do doente.

Mas o processo de conscientização da condição de alcoólatra e do entendimento do alcoolismo como doença não é algo dado e também não ocorre sem questionamentos e hesitações. Alguns entrevistados, em especial aqueles com tratamento recente, hesitam em se enquadrar naquelas atribuições, de maneira que seus depoimentos oscilam entre, por um lado, a enunciação de uma realidade médica sobre a doença e a aceitação da condição doente e, por outro, a dúvida sobre se realmente fazem parte dessa realidade.

O percurso de Rita9 é um bom exemplo. Frequentava o AA há nove meses e ingressara há apenas um mês no Serviço de Alcoolismo. Além do AA, Rita participou de vários grupos de ajuda mútua que funcionavam segundo os moldes dos chamados 12 passos, a saber: Neuróticos Anônimos, Dependentes de Amor e Sexo, Codependentes Anônimos, Devedores Anônimos, Al-anon. ${ }^{10}$ Avalia criticamente sua dificuldade de aceitação de que era alcoólatra como um problema de "negação", que ela mesma caracteriza como um dos sintomas da sua doença.

[...] como não foi uma coisa constante [o consumo de bebida], eu não me identifico como alcoólatra, porque eu acho que essa compulsão teria que ser direto, como eu ouço muito, nos depoimentos [do $\mathrm{AA}$ ], que eu fico me iludindo, achando que eu não quero ser uma alcoólatra, né, na verdade, é a negação da doença.

E complementa, mais adiante:

[...] aceitar que eu sou uma neurótica não foi difícil, aceitar que eu sou uma "codependente" não foi difícil, aceitar até que eu sou, que eu tenho um padrão de "devedores anônimos" não foi difícil. Mas "Alcoólicos Anônimos" tá sendo uma complicação na 
minha mente, porque, como eu não bebia desde 91 , sem grupo, eu achei que eu não era uma alcoólatra.

A maioria dos entrevistados que fazia acompanhamento de longa data no AA e/ou no Serviço de Alcoolismo, entretanto, se identifica sem hesitação como alcoólatra, condição associada a um modo de beber sem limite após o consumo do primeiro gole de bebida, mas também a um descontrole moral, caso em que o alcoólatra é percebido como alguém que perdeu o senso da vergonha. Os parâmetros sociais que estabelecem o limite entre o beber normal e o anormal se ancoram, portanto, num domínio moral relacionado à perda da identidade social do bebedor, o que coloca em destaque a vergonha como eixo de compreensão da reorganização moral engendrada pela carreira alcoólatra.

\section{A vergonha na carreira de tratamento}

Eu não fiz terapia. Nesses dez anos que eu fiquei sem beber eu não fiz terapia. A minha terapia, no caso, é essa vergonha. Hoje eu me entendo, né, mas não era pra ficar só aí. Era pra ter continuado, ter feito a terapia, como eu tô fazendo hoje, que me ajuda muito. (Lúcio, 62 anos, tratamento ambulatorial, nenhuma internação, inserção de longa data no Serviço de Alcoolismo.)

Juvenal ${ }^{11}$ é quem melhor sintetiza o drama do alcoólatra quando diz: "O alcoólatra, ele tem muita vergonha." Durante o estudo de campo, presenciamos a vivência da vergonha no tratamento a partir de um encontro inesperado com ele, dois meses após sua entrevista. Estávamos na sala dos técnicos, quando Juvenal apareceu alcoolizado procurando por atendimento médico. Após alguns instantes de silêncio, Juvenal disse se sentir envergonhado. Posteriormente, compreendemos a vergonha de Juvenal como uma expressão do seu sentimento de fracasso por sua "recaída", já que havia enfatizado na entrevista que, após a sua alta, cessaria definitivamente o consumo de bebida e retomaria o tratamento ambulatorial. Esse encontro com Juvenal talvez seja a melhor ilustração do efeito moral do encontro do paciente com o olhar dos agentes no espaço de tratamento no sentido de desencadear a vergonha. $\mathrm{O}$ despertar da vergonha no cenário de tratamento comprova o entrelaçamento deste sentimento com o dispositivo terapêutico e, por sua vez, a dimensão moral da medicalização do alcoolismo.

A relação entre vergonha e tratamento é ilustrada em dois momentos particulares da carreira moral alcoólatra: a primeira internação e a reinternação. 
Há uma íntima associação entre o despertar da vergonha e a confirmação pública - através dos olhares da vizinhança (no âmbito da moradia), dos internos e dos profissionais - da incapacidade de se manter sóbrio. Mas o olhar alheio provoca ou incrementa a vergonha do/a alcoólatra porque ele/a próprio já incorporou a desaprovação social em relação ao consumo de bebida. Nesse aspecto, ressaltamos o papel nada desprezível do dispositivo terapêutico de reforçar a inadequação do consumo alcoólico após o início do tratamento.

A construção da vergonha está, portanto, inevitavelmente ligada à trajetória alcoólica dos entrevistados e à consequente percepção de si como alcoólatra. A construção pessoal como doente-alcoólatra se estabelece a partir da condenação moral a um estilo passado de relação com a bebida e com o entorno.

Adriana, Angélica ${ }^{12}$ e Pedro falaram da vergonha que sentiram ao acordarem nas enfermarias do serviço. Para Pedro, a vergonha se relacionava ao olhar dos companheiros da instituição diante de sua "recaída". No caso de Adriana, associava-se à possibilidade de reencontrar sua médica na condição de interna. Adriana interrompeu o acompanhamento ambulatorial com ela, retornando apenas a partir desta internação. $\mathrm{O}$ retorno na condição de interna demonstra a não observância das orientações da médica, o que explica o comentário de que ficou "superfeliz" por saber que a médica estava de férias no período de sua internação: "Porque eu sei que ela ia me dar uma bronca, porque eu sei que eu errei, porque eu sei que eu abandonei, porque ela tinha me dito...”.

A reativação da vergonha no contexto de (re)internação sinaliza o sentimento de fracasso na manutenção da abstinência, o que, para Pedro, é suavizado pela conscientização atual de que é portador de uma doença. Ao se referir à internação, Pedro relatou: "você chega aqui, quebrado, cheio de remorso, com vergonha... quer dizer, eu chegava com vergonha, hoje em dia não, eu sei que faz parte da minha doença”. Mas nem a consciência de ser alcoólatra parece aplacar a vergonha na situação de internação. Os efeitos morais da vergonha podem se aliar ao tratamento, a ponto de ela própria adquirir uma função terapêutica.

Para Francisco, a vergonha é o que explicaria o motivo pelo qual os internos estariam menos disponíveis para a entrevista. Francisco fala dos efeitos sobre si quando passou a observar a seguinte dinâmica: alguns pacientes que saíam de alta na sexta-feira voltavam já na segunda-feira da semana seguinte. Esse fato despertou nele uma reflexão: "Aí, o Francisco, olhou pra dentro de mim, e eu 
falei comigo mesmo: 'Vem cá, não é essa vida aí que eu quero pra mim, não.' E isso foi me fortalecendo." De certa forma, é como se os pacientes internados espelhassem o que podem se tornar no futuro, caso continuem bebendo.

A dimensão terapêutica da vergonha aparece nitidamente na observação de Lúcio de que a vergonha funcionou para ele como uma terapia durante os dez anos em que ficou sem beber. Lúcio diz que, após abandonar a terapia, ficou “por conta dessa vergonha”. Assim, para ele, enquanto "durou esse sentimento de vergonha, tudo bem". O problema ocorreu posteriormente, quando achou que poderia controlar o início e o término do uso da bebida, estimulado pelo controle que conseguiu ter sobre o cigarro.

São exemplos de como a vergonha pode ser uma aliada do tratamento. Como Lúcio descreveu, o problema se inicia com a saída de cena da vergonha ou com a falta de vergonha do alcoólatra. Sem a vergonha, o alcoólatra volta a beber. Nesse sentido, podemos dizer que a vergonha é um mecanismo moral de controle do alcoolismo que impede a desmoralização do alcoólatra.

A dimensão físico-moral do alcoolismo se expressa em sua vinculação direta com o tema da desmoralização, o qual aparece na afirmação recorrente entre os membros do AA de que "o alcoolismo é uma doença que mata desmoralizando". Como bem descreveu Renato: ${ }^{13}$ "Eu nunca usei drogas, mas, pelo que falam, o alcoolismo é pior do que a droga porque ela vai te desmoralizando [...], ela tira sua identidade por completo." Mas a que tipo de identidade Renato se refere? Ricardo vincula a degradação moral suscitada pelo álcool à perda da dignidade humana. Os depoimentos sugerem que a desmoralização do alcoólatra resulta de um processo gradativo de destituição dos atributos, valores e comportamentos que compõem a identidade social do indivíduo.

Esse processo de desmoralização encontra correspondência no relato de Renato, baseado em sua própria carreira alcoólatra - do bebedor com vergonha ao alcoólatra desprovido de vergonha. Esta poderia ser dividida esquematicamente em três momentos: o primeiro, quando ainda sentia vergonha, sentimento associado ao consumo de bebida dentro de casa e longe do olhar alheio; o segundo, quando perdeu a vergonha, momento caracterizado pelo consumo alcoólico nos botequins e pela falta de cuidados básicos de higiene; e a terceira e última fase, marcada pelo retorno - agora sem qualquer resquício de vergonha - ao espaço de casa, fase que ele próprio definiu como a do "mendigo caseiro", quando bebia em 
casa por não ter mais condições físicas de ir para a rua beber.

As representaçôes em relação ao mendigo, aliás, se relacionam à imagem do "cair no chão", situação que os entrevistados tentam a todo custo evitar. O medo de cair no chão e o aspecto negativo que paira em torno da figura do mendigo podem ser interpretados a partir da observação de Fainzang (1998) sobre o "andar de quatro", que corresponde à imagem do alcoólatra na percepção dos cônjuges e ex-bebedores do grupo por ela estudado. Ele simboliza a decadência social e moral do alcoólatra, a perda de capacidades humanas devido à ruptura de atributos sociais valorizados como, por exemplo, o raciocínio e o senso moral.

A própria noção de "recaída", comumente empregada para designar o ato de voltar a beber, remete a essa decadência moral, a qual também transparece na comparação das fases da bebida com três animais, metáfora bem disseminada entre alcoólatras. São três fases descritas em ordem crescente de descenso moral: a do macaco, a do leão e a do porco. A fase do macaco é o estado inicial da embriaguez, quando o alcoólatra faz palhaçada. A fase do leão é o estágio de agressividade e incitação de briga com os outros. Já a fase do porco é marcada pelo desleixo, pela falta de mobilidade, pela proximidade com o chão, entre outras características associadas a este animal, e que podemos atrelar à descrição anterior de Renato sobre o "mendigo caseiro".

Carmem também relaciona a vergonha à desmoralização do alcoolismo quando diz: "É uma doença que lhe atinge moralmente." Carmem e Sabrina ${ }^{14}$ relatam que, em casa, não sentiam vergonha de beber. Segundo Sabrina: "Você tá na sua casa sozinha, você não fica com vergonha de... andar de quatro [...] Agora, na rua, você tem que manter... se possível, as aparências." Como é possível perceber, a divisão entre o espaço da casa e o da rua é um importante marcador da vergonha na carreira alcoólatra. O beber em casa, resguardado do olhar alheio, permite o desempenho de performances que, em público, seriam moralmente condenáveis.

Em alguns relatos, a vergonha também fornece pistas do impacto do gênero na carreira moral de homens e mulheres alcoólatras. Como no depoimento de Angélica, que relaciona a vergonha à sensação de fracasso como mãe e esposa diante de sua primeira e única internação. Na fase de campo, quando ainda estava internada, ela nos mostrou um trecho de seu diário em que descrevia sua vivência de internação. A palavra “fracasso" estava riscada a lápis, mas ainda era facilmente identificável. A esse respeito, Angélica comentou que, apesar da 
ressalva de uma colega da internação de que fracasso era uma "palavra muito forte", ela preferiu mantê-la para se lembrar do motivo pelo qual estava ali.

Atestando a repercussão do gênero sobre a configuração moral alcoólatra, percebemos que, enquanto para algumas mulheres, os conflitos morais privilegiam a tensão entre o consumo alcoólico e questôes do domínio privado (como nas consideraçóes de Angélica a respeito da dificuldade de aliar o cuidado com os filhos e o marido ao consumo de bebida), o drama do homem alcoólatra gira mais em torno do conflito entre consumo alcoólico e a adequação a uma ética de homem trabalhador e provedor da família.

No caso dos homens de camadas populares, o tema da vergonha foi central. Para Clóvis ${ }^{15}$ e Juvenal, a vergonha se destaca como um dos componentes centrais de uma ética masculina que se constitui em torno do trabalho, da família e da relação com a bebida. Ela reflete a decadência de uma moral masculina devido ao uso da bebida.

Todo o relato de Clóvis foi perpassado pelo tema do impacto do alcoolismo em seus papéis de homem, marido e pai: sua demissão do trabalho, o divórcio, o afastamento da esposa e dos filhos, a mudança de emprego e a dívida. Relacionava seu sentimento de vergonha à dívida financeira que vinha se acumulando. Assim, valorizava o sentimento de vergonha como revelador do homem honesto e com "senso de responsabilidade". Nesse sentido, seu comentário de que "só tem vergonha quem é honesto" mostra a positivação da vergonha como expressão da manutenção da ética masculina em situações moralmente condenáveis, tais como a dívida financeira, o desemprego e o uso da bebida.

Os relatos evidenciam que a passagem pelo tratamento propicia uma construção e um posicionamento singulares em relação à moral da vergonha. De acordo com Peristiany (1965), o par honra/vergonha faz parte do sistema de regras sociais de maneira que todas as sociedades teriam suas formas de honra e vergonha como dois polos de valorização social que promovem a hierarquização entre os indivíduos. $\mathrm{Na}$ análise realizada na região da Andaluzia, Pitt-Rivers (1965) observa a possível intercambialidade entre esses dois polos. Sendo assim, de modo semelhante à honra, a vergonha consiste, segundo este autor, na preocupação com a reputação e o que faria uma pessoa sensível à pressão exercida pela opinião alheia. Neste aspecto, a falta de vergonha equivaleria à desonra. Essa preocupação é bem ilustrada através do receio que alguns entrevistados 
relataram de saírem de casa após terem bebido no dia anterior ou então de serem reconhecidos como reincidentes (através da recaída) no contexto hospitalar. O sentimento de vergonha é bastante atrelado, como vimos, à confirmação pública do comportamento inadequado do bebedor a partir dos "olhares" de outras pessoas, situação a que tentam a todo custo evitar.

A vergonha associada ao consumo de bebida também se expressou através dos repetidos pedidos de desculpas por parte de Renato durante a entrevista, nos momentos em que tecia julgamentos morais sobre a falta de vergonha do alcoólatra ou então sobre a "grande vergonhice" que o alcoolismo representa. A necessidade de se desculpar pela afirmação a respeito da falta de vergonha é bem ilustrativa do caráter reprovável da ausência ou perda dessa moral. Portanto, o sentimento de culpa após o consumo alcoólico, embora menos enunciado se comparado à vergonha, parece regido pelos mesmos códigos morais da vergonha, lembrando a intercambialidade do par honra/vergonha sobre a qual refere Pitt-Rivers (1971).

A vergonha expressa a introjeção de normas, hábitos e costumes (MIAGUSKO; FERREIRA, 1999). Sendo assim, o que envergonha éa inobservância da autoridade de uma regra que regula as ações em uma dada situação social (MARTINS, 1999). Sob o efeito do álcool, os entrevistados expressam vivências de rupturas de normas e condutas sociais. A vergonha é um sinal do reconhecimento da inobservância dessas normas sociais por parte dos entrevistados e da falha em sua execução, como é o caso de marcadores sociais de gênero que diferenciam o papel de homem provedor e de boa mãe.

Todavia, as diferenças de gênero entre homens e mulheres alcoólatras foram menos ressaltadas do que as semelhanças na maneira como falavam sobre si e da relação com a bebida. Como se a marca da diferença no drama do alcoólatra fosse atenuada em função da carreira moral no percurso de tratamento. A gradativa apropriação de uma racionalidade da doença é fundamental para compreender esse processo de homogeneização devido à carreira moral.

Essa homogeneização das diferenças conduz a outro ponto relevante na análise da vergonha na carreira moral de tratamento: o grau de incorporação do discurso médico-psicológico e seu efeito encobridor da construção moral do alcoolismo. A vergonha praticamente não aparece nos relatos de entrevistados oriundos de camadas médias e que travaram contato mais próximo com a abordagem psicológica através da terapia individual ou, caso específico de Neiva, ${ }^{16}$ do estudo 
de uma disciplina de psicologia na faculdade. Segundo Neiva, a abordagem da psicologia "desculpabilizaria" o/a alcoólatra ao pressupor um motivo ou causalidade que explicaria determinada ação do indivíduo. Isso o/a protegeria do julgamento moral alheio. Segundo ela:

Porque você, quando estuda psicologia, você abre os horizontes, pra cada pessoa, é um universo. Então: "Ah, por que fulano fez isso?" [...] "O que te levou a agir dessa forma?” E não é julgar, dizer: "Fulano não presta, é vagabundo."

Portanto, os efeitos de abrandamento da condenação moral promovidos pelo saber psicológico se somam ao discurso médico sobre a doença. Ainda de acordo com Neiva:

A gente tava conversando ali [...]: "Ah, o pessoal pensa que a gente é alcoólatra porque é vagabundo, é safado, é sem-vergonha." O cara falando, aí eu falei: "Ah, não tem nada a ver, [...] o alcoolismo é uma doença, tem que ser tratada, tem que ser controlada né".

As múltiplas formas de enunciação da moral da vergonha testemunham o valor dessa categoria no contexto de tratamento. Longe de apagá-la, o status de doente alcoólatra, adquirido ao longo da carreira moral de tratamento, estabelece relações complexas com esta forma de moralidade que é bastante cara à formação da identidade alcoólatra. Mesmo que em sua forma negativa caso dos relatos que se distanciam desta moral tendo como base a racionalidade médica -, a vergonha é um eixo em torno do qual a carreira alcoólatra se constitui. Argumentamos que o tratamento não neutraliza a vergonha, mas a reinscreve sob o crivo da doença. O que parece ser problemático é menos a vergonha do que sua ausência ou perda, ou então, considerando seu substituto médico-moral, a falta de responsabilidade do alcoólatra em relação ao gerenciamento da sua doença após admitido no tratamento.

\section{Da tomada de consciência à responsabilização pelo tratamento: considerações finais}

Ao longo do percurso de tratamento, uma relação particular entre vergonha, responsabilidade e conscientização da doença é estabelecida. Em um nível, a medicalização do alcoolismo promove a desestigmatização do/a alcoólatra e uma isenção da responsabilidade por esta perturbação. Isso não exime, contudo, o/a alcoólatra, uma vez consciente da doença, da responsabilidade pelo seu 
tratamento. Esta responsabilidade, que se institui pela condição de "saber-se" doente, é um dos dispositivos morais desencadeadores da vergonha na internação.

A atribuição da responsabilidade dependerá, portanto, da perspectiva em foco: a determinação da doença ou o cumprimento das prescrições médico-morais para o gerenciamento do alcoolismo. No que tange à determinação da doença, por ser algo que escapa ao controle do alcoólatra, a culpa e a responsabilidade lhe são retiradas. Mas a ausência de comando na determinação da doença não invalida a responsabilidade do/a alcoólatra em seguir as prescriçóes do tratamento e por uma mudança na relação consigo mesmo e com a bebida.

Em estudo sobre os sentidos e práticas em torno do alcoolismo por parte de membros de um grupo AA, Campos (2004) observa que, mesmo sem ser responsável pela aquisição da doença, o alcoólatra, ao ingressar no AA, adquire responsabilidade por sua recuperação. A reformulação pessoal objetivada pelo projeto terapêutico do AA pretende, assim, resgatar a responsabilidade moral do alcoólatra, já que a doutrina do AA entende que seu alcoolismo afetou não apenas o seu corpo físico, mas também a sua família e o seu trabalho.

No âmbito dos grupos terapêuticos coordenados por psicólogas do Serviço de Alcoolismo, verificamos um acento na responsabilização intrapessoal a partir do favorecimento de uma reflexão apoiada pelo saber psicanalítico. A responsabilização favorece a reflexão do paciente "para dentro", no sentido de estimular a conscientização dos aspectos emocionais que propiciaram o sofrimento de cada um. Praticamente não se falava em bebida, mas das relaçôes sócioafetivas com familiares e parceiros. A observação de Ricardo sobre a intervenção da psicóloga do serviço, com quem realizava terapia individual, ilustra a lógica da intervenção: "Não fale de álcool, não fale de droga, fale de você." O "não falar da bebida" se contrapõe a uma tendência, também observada na literatura sobre o tema (FAINZANG, 1998), de “personificação" da bebida, depositária de todos os males, como forma de "desculpabilização" do bebedor. Neste sentido, tal responsabilização terapêutica pressupõe um reposicionamento do alcoólatra diante de sua doença, de um modo mais ativo e menos vitimizado.

Vergonha e responsabilidade são valores que reconduzem a pessoa alcoólatra ao contexto moral de seu percurso de tratamento. $\mathrm{O}$ relato anterior de Clóvis de que "só tem vergonha quem é honesto" elucida bem a vergonha como um valor que qualifica o "homem honesto", ciente de sua responsabilidade moral. 
Ela irrompe justamente nos momentos em que este contrato é abalado, como nas situações de "recaída", atestada pela internação. No caso de Angélica, por exemplo, a vergonha emergiu diante do "fracasso" de manutenção dos papéis de boa mãe e esposa.

Diferentemente do que pode parecer à primeira vista, a carreira de tratamento não elimina os elos morais que participam da configuração do alcoolismo como doença no processo de conversão de status social de bebedor para alcoólatra. Cabe ressaltar que os entrevistados não são de modo algum passivos nesse processo; muito pelo contrário, são participantes ativos na formação do dispositivo médicomoral. Este entendimento condiz com a reflexão de Adam \& Herzlich (2001), segundo a qual:

$\mathrm{Na}$ maior parte dos casos, contudo, não se deve enxergar nas representações da doença ou da saúde a simples assunção, por parte dos indivíduos, de um discurso coletivo; eles não são somente os suportes de representação perfeitamente coerentes e constituídas fora deles. A elaboração por eles feita apóia-se em recursos coletivos, empregados e modulados diferentemente em função das experiências individuais e dos contextos onde se efetua esse trabalho interpretativo. (ADAM; HERZLICH, 2001, p. 83).

Em suma, a partir das vozes de homens e mulheres alcoólatras, objetivamos descortinar um sistema moral particular que se reconfigura na interação com o dispositivo terapêutico, entendido como um campo físico-moral de produção do alcoolismo e da pessoa alcoólatra. E, dessa maneira, resgatar os valores a partir dos quais homens e mulheres em tratamento para o alcoolismo percebem e organizam a experiência do alcoolismo. Assim, tratamos de demonstrar que a naturalização do alcoolismo como uma doença do indivíduo é apenas uma face de uma configuração cultural mais ampla, que estrutura seus discursos e práticas sobre a bebida.

\section{Referências}

ADAM, P.; HERZLICH, C. Sociologia da doença e da medicina. São Paulo: Edusp, 2001 (Coleção Saúde \& Sociedade).

ALCOÓliCOS ANÔNIMOS. Os doze passos e as doze tradições. 14. ed. São Paulo: Junta de Serviços Gerais de Alcoólicos Anônimos no Brasil, 2009.

ANTZE, P. Symbolic action in Alcoholics Anonymous. In: DOUGLAS, M. (Org.). Constructive drinking. Perspectives on drink from anthropology. Cambridge: Cambridge University Press, 1987. p. 149-181. 
CAMPOS, E.A. de. As representações sobre o alcoolismo em uma associação de exbebedores: os Alcoólicos Anônimos. Cad. Saúde Pública, v. 20, n. 5, p. 1379-1387, 2004.

DRULHE, M. Mémoire et socialisation. Femmes alcooliques et associations d'anciens buveurs. Cahiers internationaux de sociologie, v. LXXXV, p. 313-324, 1988.

DUARTE, L.F.D. Da vida nervosa nas classes trabalhadoras urbanas. 2. ed. Rio de Janeiro: Zahar, 1988. 290 p.

FAINZANG, S. Curar-se do álcool: antropologia de uma luta contra o alcoolismo. Niterói: Intertexto, 2007 (Coleção Consumo de bebidas alcoólicas: práticas e representações, 2). $105 \mathrm{p}$.

Entre práticas simbólicas e recursos terapêuticos: As problemáticas de um itinerário de pesquisa. Antropolítica: Revista Contemporânea de Antropologia e Ciência Política, Niterói, n. 1, p. 19-38, 2003.

. Ethnologie des anciens alcooliques. La liberté ou la mort. 2. ed. Paris: PUF, 1998. $168 \mathrm{p}$.

GARCIA, A.M. Alcoólicos Anônimos: conversão e abstinência terapêutica. Antropolítica, Niterói, v. 15, p. 39-59, 2003 a.

. "E o verbo (re)fez o homem": estudo do processo de conversão do alcoólico ativo em alcoólico passivo. Dissertação (Mestrado em Antropologia) - Programa de Pós-graduação em Antropologia, Universidade Federal Fluminense, Niterói, 2003b.

. E o verbo (re)fez o homem. Niterói: Intertexto, 2004.

GOFFMAN, E. Manicômios, prisóes e conventos. 5. ed. São Paulo: Perspectiva, 1996. 312 p. MARIZ, C.L. Alcoolismo, gênero e pentecostalismo. Religiāo e Sociedade, v. 16, n. 3, p. 80-93, 1994a.

. "Embriagados do Espírito Santo": reflexôes sobre a experiência pentecostal e o alcoolismo. Antropolítica, Niterói, v. 15, p. 71-80, 2003.

. Libertação e ética. Uma análise do discurso de pentecostais que se recuperaram do alcoolismo. In: ANTONIAZZI et al. (Orgs.). Nem anjos nem demônios: interpretaçôes sociológicas do pentecostalismo. Petrópolis: Vozes, 1994b. p. 204-224.

MARTINS, J. de S. Introdução. O decoro nos ritos de interação na área metropolitana de São Paulo. In: (Org.). Vergonha e decoro na vida cotidiana da metrópole. São Paulo: Hucitec, 1999. 175 p.

MIAGUSKO, E.; FERREIRA, L.M.P. Circunstantes e coadjuvantes na interação social: o poder da vergonha. In: MARTINS, J.S. (Org.).Vergonha e decoro na vida cotidiana da metrópole. São Paulo: Hucitec, 1999. 175 p.

PERISTIANY, J.G. (Org.). Honra e vergonha: valores das sociedades mediterrâneas. Lisboa: Calouste Gulbenkian, 1965. 
PITT-RIVERS, J. Honra e posição social. In: PERISTIANY, J.G. (Org.). Honra e vergonha: valores das sociedades mediterrâneas. Lisboa: Calouste Gulbenkian, 1965. p. 13-59.

SOARES, B.M. Mulheres invisiveis: violência conjugal e as novas políticas de segurança. Rio de Janeiro: Civilização Brasileira, 1999.

\section{Notas}

${ }^{1} \mathrm{O}$ artigo é resultado de pesquisa de doutorado, defendida no IMS-UERJ sob orientação da Profa. Dra. Fabíola Rohden e obedeceu às normas constantes na Resolução 196/96. O doutorado contou com o apoio financeiro da CAPES nos primeiros meses.

${ }^{2} \mathrm{O}$ termo "alcoólatras" é empregado para designar os homens e as mulheres que participam de instituiçôes de enfrentamento do alcoolismo. Assim, chamamos a atenção para a consolidação de uma identidade através do percurso de tratamento.

${ }^{3}$ Ricardo, 54 anos, tratamento ambulatorial no momento da entrevista, inserção de longa data no AA.

${ }^{4}$ O Serviço de Alcoolismo é formado por profissionais de saúde (psicólogos, psiquiatras, clínicos e enfermeiros), ao passo que o AA se originou e se mantém até hoje a partir da troca de experiências de ex-bebedores sobre sua experiência alcoólica.

${ }^{5}$ Como tratamento de longa data, consideramos a inserção institucional de duração maior que dois anos.

${ }^{6} \mathrm{O}$ aspecto central da instituição total é a ruptura de barreiras que separam o dormir, o brincar e o trabalhar, de modo que todos os aspectos da vida são realizados sob um plano racional único (GOFFMAN, 1996).

${ }^{7}$ Pedro, 54 anos, tratamento ambulatorial no momento da entrevista, várias internações, inserção de longa data no Serviço de Alcoolismo.

${ }^{8}$ Ana, 52 anos, tratamento ambulatorial, nenhuma internação, inserção recente no Serviço de Alcoolismo e de longa data no AA.

${ }^{9}$ Rita, 46 anos, tratamento ambulatorial, inserção recente no Serviço de Alcoolismo e no AA.

${ }^{10}$ São grupos que funcionam nos moldes dos 12 Passos e das 12 Tradições do AA. (ver ALCOÓLICOS ANÔNIMOS, 1999). O Al-anon é um programa para familiares e amigos de alcoólatras.

${ }^{11}$ Juvenal, 55 anos, internado no momento da entrevista, várias internações, inserção de longa data no Serviço de Alcoolismo.

${ }^{12}$ Adriana, 54 anos, tratamento ambulatorial no momento da entrevista, tratamento de longa data no Serviço de Alcoolismo. Angélica, 50 anos, primeira internação no momento da entrevista, inserção recente no Serviço de Alcoolismo.

${ }^{13}$ Renato, 48 anos, tratamento ambulatorial no momento da entrevista, inserção de longa data no Serviço de Alcoolismo.

${ }^{14}$ Sabrina, 45 anos, internada no momento da entrevista, várias internaçôes hospitalares, adepta de longa data do AA e inserção recente no Serviço de Alcoolismo.

${ }^{15}$ Clóvis, 62 anos, internado no momento da entrevista, inserção recente no Serviço de Alcoolismo.

${ }^{16}$ Neiva: 44 anos, internada no momento da entrevista, inserção de longa data no Serviço de Alcoolismo. 


\section{The moral career of shame from the viewpoint of "alcoholic" men and women}

This paper analyzes the moral career of alcoholism treatment in a public health facility, with testimonials from "alcoholic" men and women on the moral of shame. The moral career is the sequence of changes that affect the scheme of identity and images with which a person judges others and herself. We interviewed 20 patients out of which, ten men and ten women, who were either outpatients or hospitalized. Furthermore, field observations of the relationship between patients and those with health professionals were conducted. Moral career aspects were analyzed, among which, the "awareness" of alcoholism and the alcoholic condition as well as the construction of shame and responsibility in the context of treatment. Shame expresses the recognition of respondents about the disregard of social norms, such as the impact of gender in defining both the ethics of the male provider and the good mother. Proving the moral dimension of medical therapeutic device, shame is reconfigured in moments of (re) admission as an expression of a disapproved drinking lifestyle, and joins the therapeutic project in order to hamper the "relapse" and prevent the alcoholic demoralization. We conclude that the medicalization of alcoholism is inscribed in an encompassing moral field that produces moralities and particular ways of perceiving and dealing with alcoholism.

Key words: moral career; shame; alcoholism; treatment. 